\title{
Nurses' knowledge and responsibility toward nutritional assessment for patients in intensive care units
}

\author{
Mahmoud Al Kalaldeh*, Mahmoud Shahin² \\ ${ }^{1}$ Faculty of Nursing, Zarqa University, Zarqa, Jordan, ${ }^{2}$ Faculty of Nursing, Isra University, Amman, Jordan
}

\begin{abstract}
Introduction: Nutritional assessment is a prerequisite for nutritional delivery. Patients in intensive care suffer from under-nutrition and nutritional failure due to poor assessment. Nursing ability to early detect nutritional failure is the key for minimizing imparities in practice and attaining nutritional goals. Aim of this article is to examine the ability of Jordanian ICU nurses to assess the nutritional status of critically ill patients, considering biophysical and biochemical measures.

Methods: This cross sectional study recruited nurses from different health sectors in Jordan. ICU nurses from the governmental sector (two hospitals) and private sectors (two hospitals) were surveyed using a self-administered questionnaire. Nurses' knowledge and responsibility towards nutritional assessment were examined.
\end{abstract}

Results: A total of 220 nurses from both sectors have completed the questionnaire. Nurses were consistent in regard to knowledge, responsibility, and documentation of nutritional assessment. Nurses in the governmental hospitals inappropriately perceived the application of aspiration reduction measures. However, they scored higher in applying physical examination and anthropometric assessment. Although both nurses claimed higher use of biochemical measurements, biophysical measurements were less frequently used. Older nurses with longer clinical experience exhibited better adherence to biophysical measurement than younger nurses.

Conclusion: Nursing nutritional assessment is still suboptimal to attain nutritional goals. Assessment of body weight, history of nutrition intake, severity of illness, and function of gastrointestinal tract should be considered over measuring albumin and pre-albumin levels. A well-defined evidence-based protocol as well as a multidisciplinary nutritional team for nutritional assessment is the best to minimize episodes of under-nutrition.

Keywords: assessment; nutritional status; nurse

\footnotetext{
*Corresponding author: Mahmoud Al Kalaldeh, PhD RN MSN CNS, Faculty of Nursing, Zarqa University, Zarqa, Jordan

Phone: +962 53821100 ,

E-mail: kalaldeh82@yahoo.com
}

Submitted July 212014 / Accepted August 212014

\section{INTRODUCTION}

Critical illness is associated with many complications such as anorexia, hyper metabolism, malabsorption; atrophy of muscles, liver, kidney, gastrointestinal tract \& heart; impaired cell mediated immunity, 
susceptibility to infections, poor wound healing, anemia, death $(1,2)$. Enteral nutrition $(\mathrm{EN})$ is the preferred nutritional method whenever is possible to feed critically ill patients $(3,4)$. When gut is used for nutrition, bacterial translocation and septicemia are prevented.

Malnutrition is a term used frequently in healthcare system which is the analogy of under-nutrition or inadequate energy intake less than the metabolic demands $(5,6)$. Under-nutrition can also be resulted from abnormal digestion or absorption of protein and calories $(5,6)$. It is also acknowledged that malnutrition in the critically ill is associated with impaired immune functions; impaired ventilator drive, and weakened respiratory muscles, leading to prolonged ventilator dependence and increased infectious morbidity and mortality $(7,8)$.

Proper nutritional assessment is strongly linked to successful nutritional plans for critically ill patients $(4,9,10)$. The current focus on nutrition in critical care settings is that carefully selecting patient's parameters that would highly reflect patient's outcome (11-13). In order to design an appropriate and effective strategy for nutritional assessment in the intensive care, a crucial guidelines have to be applied systematically for all critically ill patients $(14,15)$.

Nurses in intensive care are in a key position to maintain patients' nutritional status at an optimal level and closer to the nutritional goals $(16,17)$. While most of the critical care nurses are responsible for establishing nutritional access and initiating feeding, in some instances, they calculate the caloric needs according to the body requirements and measure the daily calories delivered $(16,17)$. However, imparity in nursing practices contributes to developing serious deficiencies and complications due lack of unified guidelines $(18,19)$. When adherence to evidence-based guidelines is assured, the discrepancy inherent in nursing practice can be curtailed and the effectiveness of nutritional practices are maintained $(20,21)$.

In Jordan, critical care nurses have no obvious role regarding nutritional care (22). While dietitians are available in the most of Jordanian hospitals, nurses often hold the responsibility for early detecting the sings of under-nutrition and assessing the outcomes of the delivered feeding although lack of expertise and training is sometime evident $(23,24)$. Unfortunately, a limited number of tools for nutritional assessment are available in the Jordanian hospitals; in addition to poor academic preparations that suffice this domain (22).

The most recommended nutritional assessment tools are as follows: (a) biophysical assessment and anthropometric measurement which include body mass index (BMI), mid-arm muscle circumference, triceps skin fold thickness, in addition to measuring Gastric Residual Volume (GRV) and detecting tube placement for enteral fed patients $(16,17)$. However, the ratio of subcutaneous layer to total body fat may vary from $20 \%$ to $70 \%$ in the normal individuals; so they are not recommended in extreme weight change due to the risk for overestimating body fat in malnourished patients (16). (b) Physical examination which includes history of weight loss, alcohol abuse, dietary habits, skin, mouth, and neurological system monitoring $(25,26)$. Body temperature is also a part of the physical examination $(27,28)$. (c) Biochemical assessment includes serum albumin, transferrin, transthyretin (prealbumin), retinol-binding protein, somatolin $\mathrm{C}$ and fibronectin $(29,30)$. However, changes in fluid distribution may result in pseudo rise or fall in the value of albumin level causing false medical interpretation (31). (d) Dietary assessment which includes 24 hours recall, food records (diaries), diet history and food frequency questionnaires (32). These methods may however be impractical for critically ill patients who are unable to communicate effectively with practitioners $(18,33)$.

The purpose of this study was to assess Jordanian nurses' knowledge and responsibility of nutritional assessment in the critical care, considering biophysical and biochemical measures.

\section{METHODS}

This descriptive cross sectional study employed nurses from four hospitals in Jordan; two governmental hospitals and two private hospitals. It is assumed that there are many differences between heath care sectors in Jordan in terms of medical protocols and nursing practice (22). For that reason, nurses in different heath care sectors may exhibit 
various level of adherence to nutritional assessment tools. Nurses working in any intensive care units and had at least one year of clinical experience and hold the bachelors or diploma degree in nursing was eligible for participation. Convenient sampling technique was used to select participants from each involved hospital. The estimation of sample size was based on the medium effect size, power of 0.80 , and $\alpha$ of 0.05 (34). All selected hospitals are located in Amman, the capital of Jordan, and all are considered as major and referral hospitals that operate well occupied intensive care units.

Study instrument included a self-administered questionnaire developed to assess nurses' ability to assess patients' nutritional status while staying in the intensive care. This questionnaire consisted of five demographic questions; six questions related to the attitudes towards nutritional assessment including aspiration-reduction measures; and five questions related to using different bio-physical and biochemical measures. The scoring system ranged from 1 (to a very small extent) to 5 (very great extent). A pilot study was carried out by 10 nurses from the same study target to test the clarity, applicability, and feasibility of the questionnaire. Minor modifications were done after piloting and those nurses participated in the pilot study were excluded from the study sample. The content validity was also assessed by a panel of experts in this field, including a physician, a dietitian, and two expert nurses.

Ethical approvals were anticipated from each hospital's authority prior to data collection. A written permission (informed consent) for participation was obtained from each participant after providing complete information about the study and its significance. Anonymous participations and confidentiality of data were also assured. Data were collected in collaboration with the head nurses of the unit in which they contributed in selecting the eligible participants, handing, and returning the completed questionnaires in a sealed envelope within one week.

\section{Statistical analysis}

After returning all completed questionnaires, data were entered the statistical package for social sciences (SPSS) software, version 17. Descriptive statistics including number, percent, mean, Standard Deviation (SD) were used and followed by comparing differences between study groups using Chi-square and Kruskal-Wallis test.

\section{RESULTS}

\section{Participants' demographics}

A total of two hundred and twenty intensive care nurse participated in the study and returned the completed questionnaires. As shown in Table 1, the majority of the study participants were female accounting 65\% while 34\% were male. Regarding the ages, around $38 \%$ were aged less than 25 years old and the second majority age group was between 25-45 years old. About the half of the sample had a clinical experience of less than five years and very few had an experience of more than 20 years. While the majority of participants (71.4\%) hold the bachelor degree of nursing, the vast majority (82.3\%) claimed no previous clinical training received with the respect of nutritional assessment (Table 1).

TABLE 1. Participants' demographics

\begin{tabular}{llccc}
\hline Variable & Category & $\begin{array}{c}\text { Governmental } \\
\mathrm{n}(\%)\end{array}$ & $\begin{array}{c}\text { Private } \\
\mathrm{n}(\%)\end{array}$ & $\begin{array}{c}\text { Total } \\
\mathrm{n}(\%)\end{array}$ \\
\hline Gender & Male & $46(35.7)$ & $31(34.1)$ & $77(35)$ \\
& Female & $83(64.3)$ & $60(65.9)$ & $143(65)$ \\
& Total & $129(100)$ & $91(100)$ & $220(100)$ \\
Age & $<25$ & $51(39.6)$ & $33(36.3)$ & $84(38.1)$ \\
& $25-35$ & $33(25.5)$ & $25(27.5)$ & $58(26.4)$ \\
& $36-45$ & $29(22.5)$ & $25(27.5)$ & $54(24.6)$ \\
& $>45$ & $16(12.4)$ & $8(8.7)$ & $24(10.9)$ \\
Years of & Total & $129(100)$ & $91(100)$ & $220(100)$ \\
experience & $<1$ & $36(27.9)$ & $26(28.5)$ & $62(28.2)$ \\
& $1-5$ & $28(21.7)$ & $17(18.7)$ & $45(20.5)$ \\
& $6-10$ & $24(18.6)$ & $15(16.5)$ & $39(17.7)$ \\
& $11-15$ & $24(18.6)$ & $16(17.6)$ & $40(18.2)$ \\
& $16-20$ & $12(9.3)$ & $9(9.9)$ & $21(9.5)$ \\
& $>20$ & $5(3.9)$ & $8(8.8)$ & $13(5.9)$ \\
& Total & $129(100)$ & $91(100)$ & $220(100)$ \\
Level of & Diploma & $45(34.9)$ & $18(19.8)$ & $63(28.6)$ \\
Education & Bachelor & $84(65.1)$ & $73(80.2)$ & $157(71.4)$ \\
& Total & $129(100)$ & $91(100)$ & $220(100)$ \\
Attending & Yes & $13(10.1)$ & $26(28.6)$ & $39(17.7)$ \\
Courrition & No & $116(89.9)$ & $65(71.4)$ & $181(82.3)$ \\
\hline & Total & $129(100)$ & $91(100)$ & $220(100)$ \\
\hline
\end{tabular}




\section{Attitudes to nutritional assessment}

As shown in Table 2, the nurses showed a consistent adherence to the use of nutritional assessment in the ordinary nursing process. There were no any significant differences between nurses from both groups in relation to the importance of assessment in acquiring knowledge, having responsibility, and documenting nutritional changes. Scores were mainly above the midpoint of 2.5 , indicating that nurses perceived the importance of assessment through their nursing process. Regarding some nutritional assessment tools, nurses in the private sectors claimed measuring gastric aspirate more frequently than nurses in governmental sectors. Similarly, detecting tube placement was also scored higher among nurses in the private sectors than governmental nurses. In addition, nurses in the private hospitals claimed using other aspiration reduction measures such as degree of head of the bed, controlling feeding rates, and using of promotility agents more frequently than nurses in the governmental hospitals.

\section{Adherence to various nutrition assessment tools}

This section shows nurses' attitudes towards adherence to various nutritional assessment tasks while providing EN care for critically ill patients. There were a statistical significant differences between governmental and private sector nurses in regard to adherence to these nutritional assessment provisions. Nurses in the governmental hospitals scored significantly higher in undertaking assessment using physical examination, anthropometric assessment, and dietary assessment than nurses working in the private sector. However, both groups had equally showed the extent of using biomedical assessment and screening for nutritional risks as main tools for assessing the nutritional status (Table 3).

\section{Variations in nutritional assessment between demographic groups}

While no significant differences between male and female nurses in regard to the adherence to nutritional assessment, older nurses with longer clinical experience scored higher in applying a nutritional assessment using biophysical measurements $\left(x^{2}=24.261, d f=3, p=0.043\right)$. However, younger nurses with shorter clinical experience scored higher in having a nutritional assessment using biochemical measurements $\left(\mathrm{x}^{2}=35.171, \mathrm{df}=3, \mathrm{p}<0.001\right)$. Although bachelor and diploma degree holders did not differ significantly in term of nutritional assessment, nurses who received previous nutritional training were more likely to adhere to different assessment measures than those who did not $\left(\mathrm{x}^{2}=76.184, \mathrm{df}=1, \mathrm{p}<0.001\right)$.

\section{DISCUSSION}

It was evident that nurses well perceived the knowledge and responsibility for nutritional assessment and claimed competency in undertaking nutritional assessment while examining the effectiveness of delivered feeding. This premise is supported by other researchers who reinforced the importance of nutritional assessment as the first step of nutritional care $(14,35,36)$.

Aspiration is the most common dangerous side effect resulting from EN. Aspiration-reduction measures can be applied individually; however, most of them are combined into one protocol especially in patients with mechanical ventilation. For instance, Bowman et al. (2005) established and implemented a new 'evidence-based feeding protocol' and an

TABLE 2. Attitude to nutritional assessment

\begin{tabular}{|c|c|c|c|c|c|c|c|c|}
\hline & \multicolumn{2}{|c|}{ Governmental $(n=129)$} & \multicolumn{2}{|c|}{ Private $(n=91)$} & \multicolumn{2}{|c|}{ Total $(n=220)$} & \multicolumn{2}{|c|}{ Kruskal-Wallis test } \\
\hline & M & SD & $\mathrm{M}$ & SD & M & SD & $\chi^{2}$ test & $p$-value \\
\hline Knowledge of assessment & 2.79 & 1.28 & 3.22 & 1.22 & 2.97 & 1.21 & 5.782 & 0.056 \\
\hline Responsibility of assessment & 2.87 & 1.19 & 3.26 & 1.11 & 3.03 & 1.13 & 5.696 & 0.058 \\
\hline Documentation of assessment & 3.13 & 1.32 & 3.00 & 1.08 & 3.01 & 1.17 & 1.598 & 0.450 \\
\hline Measuring gastric aspirates & 3.14 & 1.36 & 4.05 & 1.29 & 3.70 & 1.33 & 25.909 & $<0.001$ \\
\hline Detecting tube placement & 3.88 & 1.31 & 4.31 & 0.93 & 4.00 & 1.14 & 10.176 & 0.006 \\
\hline Other aspiration reduction measures & 3.06 & 1.19 & 3.59 & 0.99 & 3.27 & 1.14 & 9.249 & 0.010 \\
\hline
\end{tabular}

Scores range from 1 (to a very small extent) to 5 (very great extent) * M: Mean, ${ }^{*}$ SD: Standard deviation 
TABLE 3. Adherence to nutritional assessment

\begin{tabular}{|c|c|c|c|c|}
\hline & \multirow{2}{*}{$\begin{array}{c}\text { Governmental } \\
\text { Mean }(S D)(n=129)\end{array}$} & \multirow{2}{*}{$\begin{array}{c}\text { Private } \\
\text { Mean (SD) }(n=91)\end{array}$} & \multicolumn{2}{|c|}{ Kruskal-Wallis test } \\
\hline & & & $\chi^{2}$ test & $p$-value \\
\hline Physical examination & $2.28(1.03)$ & $1.48(0.87)$ & 22.43 & $<0.001$ \\
\hline Anthropometric assessment & $2.56(1.35)$ & $1.74(1.08)$ & 19.65 & $<0.001$ \\
\hline Dietary assessment & $4.31(0.93)$ & $3.79(1.09)$ & 24.09 & $<0.001$ \\
\hline Biochemical assessment & $3.51(1.33)$ & $3.69(1.09)$ & 5.54 & 0.590 \\
\hline Screening for nutritional risks & $3.27(1.64)$ & $3.46(1.23)$ & 8.17 & 0.360 \\
\hline
\end{tabular}

Scores range from 1 (to a very small extent) to 5 (very great extent)

'aspiration reduction algorithm' for enteral fed, mechanically ventilated patients in the ICUs. Also, Metheny et al. (2010) evaluated the effectiveness of using 'Aspiration Risk-Reduction Protocol' (ARRP) for enteral fed patients with mechanical ventilation. The importance of controlling GRVs was adequately perceived by nurses as a protective measure to prevent higher GRV limits $(28,37)$. This conforms to the evidence-based recommendations that measuring GRV is an essential element in EN and should be maintained under the universal threshold of $200-500 \mathrm{ml}$ (10). It is also accepted to define GRV as the cutoff point of $30 \%$ of the last given feeding amount which is remaining in the stomach $(38,39)$. However, previous studies addressed that GRVs should not be taken into account for all potential risks for pulmonary aspiration, the evidence showed that many other factors should be considered along with GRVs to reduce the risk of aspiration such as trauma, head injury, using of sedation, and mental instability (40). A number of other recommendations are helpful to accomplish nutritional goals such as avoiding inappropriate feeding cessation, using prokinetic agents with EN, keeping the head of the bed elevated at $35-45^{\circ}$, increasing feeding rate in a constant manner and using pre-prepared feeding packs $(10,41,42)$.

Studies stressed on the regular checking for tube position which is strongly associated with low complication incidences. Feeding tube should be checked regularly before each feeding administration or at least every day using a reliable indicator such as radiographic confirmation (X-ray) which is still considered as a 'gold standard' (43-45). Measuring $\mathrm{pH}$ of gastric aspirate is another reliable indicator for tube placement. However, studies have confirmed that radiography is superior to other technique despite the risk of radiation exposure, but if not available, $\mathrm{pH}$ method can be applied $(10,38,46-50)$.

The use of bio-physiological and bio-chemical parameters such as body weight, abdominal girth, bowel exam, skin integrity, and urine and stool analysis in addition to serum protein level in the blood were assessed in this study. The nurses showed a higher reliance on the bio-chemical indicator than bio-physical measurement. Previous studies revealed that not all patients in intensive care have a regular nutritional assessment and the essential aspects of nutritional documentation are missing $(23,51)$. Also, it is unlikely to have entire screening tool for evaluating nutritional outcomes $(52,53)$. Evidence-based guidelines stressed on investigating weight, history of nutrition intake, severity of illness, and function of gastrointestinal tract prior to admission instead of measuring albumin and pre-albumin $(10,54)$. The frequent assessment of BMI should also be measured by dividing weight in kilograms by the square of the height in meters (Normal range 19-25) (55). In general, all studies confirmed the significance of using evidence-based guidelines for nutritional assessment as the majority of nurses showed inconsistency in having the systematic tools for measuring nutritional outcomes (52).

Although the study recruited sample from two heath care sectors in Jordan, involving the other heath sectors such as the military heath sector would enhance the external validity of the study. In addition, including other hospitals from different geographical location, away from the capital, would provide further understanding about the phenomenon and enhance generalizability.

Nurses require understanding factors associated with under-nutrition and hypo-caloric feeding through undertaking such nutritional assessment 
measures that assist to early detecting the risk for these episodes. The application of bio-physical measurements in the intensive care is still deficient so further insight about the usefulness of these measures should practically be applied.

Future researchers are invited to conduct other extensive research works that involve more aspects about nutritional care. Investigating the role of multidisciplinary work is also a priority to provide further understanding about the role of physicians and dietitians in assessing patients' nutritional status while being in the intensive care.

\section{CONCLUSION}

Nursing nutritional assessment is still suboptimal to promote patients' successful nutrition. The impact of nutritional assessment on determining the patients' status and detecting some complications such as aspiration pneumonia is well-known, but nurses need to underpin their practice with some evidence-based guidelines to manage these issues effectively.

This study provides overview to the body of knowledge about the role of intensive care nurses in maintaining optimal nutritional therapy In Jordan. Awareness about the current feature of nutritional assessment sheds the light on the future development strategies. In eventual, nurses' practitioners would emphasize of the role of training to improve their professional competency in the light of nutritional delivery in the critically ill.

\section{CONFLICT OF INTEREST}

The authors declare that they have no competing interests.

\section{ACKNOWLEDGMENT}

Authors are indebted to all nurses participated in this study including nursing staff, head nurses, and nurse managers.

\section{REFERENCES}

1. Feldblum I, German L, Bilenko N, A. S, Enten R, Greenberg D, et al. Nutritional risk and health care use before and after an acute hospitalization among the elderly. Nutrition. 2009;25:415-20. http://dx.doi. org/10.1016/j.nut.2008.10.016.
2. Schiesser M, Kirchhoff $P$, Müller M, Schfer M, Clavien $P$. The correlation of nutrition risk index, nutrition risk score, and bioimpedance analysis with postoperative complications in patients undergoing gastrointestinal surgery. Surgery. 2009;145(5):519-26. http://dx.doi.org/10.1016/j. surg.2009.02.001.

3. Heyland DK, Dhaliwal R. Early enteral nutrition vs. early parenteral nutrition: an irrelevant question for the critically ill? Critical Care Medicine. 2005;33(1):260-1. http://dx.doi.org/10.1097/01. CCM.0000150749.13940.37.

4. Heighes P, Doig G, Sweetman E, Simpson F. An overview of evidence from systematic re-views evaluating early enteral nutrition in critically ill patients: more convincing evidence is needed. Anaesth Intensive Care. 2010;38:167-74.

5. Hofhuis J, Spronk P, van Stel H, Schrijvers A, Rommes J, Bakker J. Experiences of critically ill patients in the ICU. Intensive and Critcal Care Nursing. 2008;24(5):300-13. http://dx.doi.org/10.1016/j.iccn.2008.03.004.

6. Huber $\mathrm{O}$. Hospitalized mechanically ventilated patients are at higher risk of enteral underfeeding than non-ventilated patients. Clinical Nutrition. 2006;25(5):727-35. http://dx.doi.org/10.1016/j.clnu.2006.03.011.

7. Casaer M, Mesotten D, Hermans $G$. Early versus late parenteral nutrition in critically ill adults. N Engl J Med. 2011;DOI: 10.1056/NEJMoa1102662. http://dx.doi.org/10.1056/NEJMoa1102662.

8. Kang W, Gomez F, Lan J, Sano Y, Ueno C, Kudsk K. Parenteral nutrition impairs gut-associated lymphoid tissue and mucosal immunity by reducing lymphotoxin beta receptor expression. Ann Surg. 2006;244:392-9.

9. Jones NE, Heyland DK. Implementing Nutrition Guidelines in the Critical Care Setting; A Worthwhile and Achievable Goal? Journal of American Medical Association. 2008;300(23):2798-9. http://dx.doi.org/10.1001/ jama.2008.814.

10. McClave SA, Martindale RG, Vanek VW, McCarthy M, Roberts $P$, Taylor B, et al. Guidelines for the Provision and Assessment of Nutrition Support Therapy in the Adult Critically III Patient:. Journal of Parenteral and Enteral Nutrition. 2009;33(3):277-316. http://dx.doi. org/10.1177/0148607109335234.

11. Correia M, Campos A. Prevalence of hospital malnutrition in Latin America: the multicenter ELAN study. Nutrition. 2003;19:823-5. http://dx.doi. org/10.1016/S0899-9007(03)00168-0.

12. Cahill NE, Murch L, Jeejeebhoy K, McClave SA, Day AG, Wang M, et al. When early enteral feeding is not possible in critically ill patients: results of a multicenter observational study. JPEN Journal of Parenteral \& Enteral Nutrition. 2011;35(2):160-8. http://dx.doi.org/10.1177/0148607110381405.

13. Fang JC, Delegge MH. Enteral feeding in the critically ill: the role of the gastroenterologist. American Journal of Gastroenterology. 2011;106(6):1032-7. http://dx.doi.org/10.1038/ajg.2011.77.

14. Anthony P. Nutrition screening tools for hospitalized patients. Nutrition in Clinical Practice. 2008;23:373-82. http://dx.doi. org/10.1177/0884533608321130.

15. Campillo B, Richardet J, Bories P. Validation of body mass index for the diagnosis of malnutrition in patients with liver cirrhosis. Gastroenterol Clin Biol. 2006;30:1137-43. http://dx.doi.org/10.1016/S0399-8320(06)73491-1.

16. Christensson L, Unosson M, Ek A. Evaluation of nutritional assessment techniques in elderly people newly admitted to municipal care. European Journal of Clinical Nutrition. 2002;56(9):810-7. http://dx.doi.org/10.1038/ sj.ejcn.1601394.

17. O'Meara D, Mireles-Cabodevila E, Frame F, Hummell C, Hammel J, Dweik RA, et al. Evaluation of delivery of enteral nutrition in critically ill patients receiving mechanical ventilation. American Journal of Critical Care. 2008;17(1):53-61.

18. BeckA, Holst M, Rasmussen H. Efficacy of the Mini Nutritional Assessment to predict the risk of developing malnutrition or adverse health outcomes for old people. The European e-Journal of Clinical Nutrition and Metabolism. 2008;3(3):102-7. http://dx.doi.org/10.1016/j.eclnm.2008.03.001.

19. Heyland DK, Stephens KE, Day AG, McClave SA. The success of 
enteral nutrition and ICU-acquired infections: A multicenter observational study. Clinical Nutrition. 2011;30(2):148-55. http://dx.doi.org/10.1016/j. clnu.2010.09.011.

20. Engel J, Muhling J, Junger A, Menges T, Karcher B, Hempelmann G. Enteral nutrition practice in a surgical intensive care unit: what proportion of energy expenditure is delivered enterally? Clinical Nutrition. 2003;22(2):187-92. http://dx.doi.org/10.1054/clnu.2002.0622.

21. Metheny NA, Jackson D, Stewart BJ. Effectiveness of an Aspiration RiskReduction Protocol. Nursing Research. 2010;59(1):18-25. http://dx.doi. org/10.1097/NNR.0b013e3181c3ba05.

22. Al-Kalaldeh M, Watson R, Hayter M. Jordanian nurses' knowledge and responsibility for enteral nutrition in the critically ill. Nursing in Critical Care. 013; DOI: 10.1111/nicc.12065. http://dx.doi.org/10.1111/nicc.12065.

23. Higgins PA, Daly BJ, Lipson AR, Guo S. Assessing nutritional status in chronically critically ill adult patients. American Journal of Critical Care. 2006;15(2):166-77.

24. Bowman A, Greiner JE, Doerschug KC, Little SB, Bombei CL, Comried LM Implementation of an Evidence-based Feeding Protocol and Aspiration Risk Reduction Algorithm. Critical Care Nursing Quarterly. 2005;28(4):324-33. http://dx.doi.org/10.1097/00002727-200510000-00004.

25. Davidson I, Smith S. Nutritional screening: pitfalls of nutritional screening in the injured obese patient. Proc Nutr Soc. 2004;36(3):421-5. http://dx.doi. org/10.1079/PNS2004371

26. Fletcher A, Carey E. Knowledge, attitudes and practices in the provision of nutritional care. British Journal of Nursing (BJN). 2011;20(10):615-20. http://dx.doi.org/10.12968/bjon.2011.20.10.615.

27. Belafsky P, Mouadeb D, Rees C. Validity and reliability of the Eating Assessment Tool (EAT-10). Ann Otol Rhinol Laryngol. 2008;717:919-24.

28. Metheny NA, Schallom L, Oliver DA, Clouse RE. Gastric residual volume and aspiration in critically ill patients receiving gastric feedings. American Journal of Critical Care. 2008;17(6):512-20.

29. Weekes C, Elia M, Emery P. The development, validation and reliability of a nutrition screening tool based on the recommendations of the british association for parenteral and enteral nutrition (BAPEN). Clinical Nutrition. 2004;23(5):1104-12. http://dx.doi.org/10.1016/j.clnu.2004.02.003.

30. Beecroft C, Booth A, Rees A. Finding the Evidence. In: Gerrish K, Lacey A, editors. The Research Process in Nursing. Oxford: Wiley-Blackwell; 2010.

31. Thorsdottir I, Gunnarsdottir I, Eriksen B. Screening method evaluated by nutritional status measurements can be used to detect malnourishment in chronic obstructive pulmonary disease. J Am Diet Assoc. 2001;101:648-54. http://dx.doi.org/10.1016/S0002-8223(01)00163-8.

32. Thorsdottir I, Jonsson P, Asgeirsdottir A, Hjaltadottir I, Bjornsson S, A. R. Fast and simple screening for nutritional status in hospitalized, elderly people. J Hum Nutr Dietet. 2005;18:53-60. http://dx.doi. org/10.1111/j.1365-277X.2004.00580.x

33. Green $S$, Watson R. Nutritional screening and assessment tools for use by nurses: Literature review. Journal of Advanced Nursing. 2005;50(1):69- 83. http://dx.doi.org/10.1111/j.1365-2648.2004.03350.x.

34. Cohen J. Quantitative Methods in Psychology. Psychological Bulletin. 1992;112(1):155-9. http://dx.doi.org/10.1037/0033-2909.112.1.155

35. Joiliet P, Pichard C, Biolo G, Chiolero R, Grimble G, Leverve X, et al. Enteral nutrition in intensive care patients: a practical approach. Intensive Care Medicine. 1998;24:848-59. http://dx.doi.org/10.1007/s001340050677.

36. Doig GS, Simpson F, Finfer S, Delaney A, Davies AR, Mitchell I, et al. Effect of Evidence-Based Feeding Guidelines on Mortality of Critically III Adults; A Cluster Randomized Controlled Trial. Journal of American Medical Association. 2008;300(23):2731-41. http://dx.doi.org/10.1001/ jama.2008.826.

37. DeLegge MH. Managing gastric residual volumes in the critically ill patient: an update. Current Opinion in Clinical Nutrition \& Metabolic Care. 2011;14(2):193-6. http://dx.doi.org/10.1097/MC0.0b013e328341ede7.

38. Padula CA, Kenny A, Planchon C, Lamoureux C. Enteral Feedings:
What the Evidence Says. AJN. 2004;104(7):62-9. http://dx.doi. org/10.1097/00000446-200407000-00034.

39. Hsu CW, Sun SF, Lee DL, Lin SL, Wong KF, Huang HH, et al. Impact of disease severity on gastric residual volume in critical patients. World Journal of Gastroenterology. 2011;17(15):2007-12. http://dx.doi.org/10.3748/wjg. v17.i15.2007.

40. McClave SA, Snider HL. Clinical Use of Gastric Residual Volumes as a Monitor for Patients on Enteral Tube Feeding. Journal of Parenteral and Enteral Nutrition. 2002;26(6):43-50. http://dx.doi. org/10.1177/014860710202600607.

41. Bourgault A, Ipe L, Weaver J, Odea P. Development of Evidence-Based Guidelines and Critical Care Nurses 'Knowledge of Enteral Feeding. Critical Care Nurse. 2007;27(4):17-29.

42. Simpson F, Doig GS. Parenteral vs. enteral nutrition in the critically ill patient: a meta-analysis of trials using the intention to treat principle. Intensive Care Medicine. 2005;31(1):12-23. http://dx.doi.org/10.1007/ s00134-004-2511-2.

43. Burns SM, Carpenter R, Blevins C, Bragg S, Marshall M, Browne L, et al. Detection of inadvertent airway intubation during gastric tube insertion: capnography versus a colorimetric carbon dioxide detector. American Journal of Critical Care 2006:15:188-93.

44. Lamont T, Beaumont C, Fayaz A, Healey F, Huehns T, Law R, et al. Checking placement of nasogastric feeding tubes in adults (interpretation of $x$ ray images): summary of a safety report from the National Patient Safety Agency. BMJ. 2011;342.

45. Williams TA, Leslie GD. A review of the nursing care of enteral feeding tubes in critically ill adults: part II. Intensive and Critical Care Nursing. 2005;21:5-15. http://dx.doi.org/10.1016/j.iccn.2004.08.003.

46. Jacobs B, Persinger M, Carver J, Moore L, Brilli R. Rapid placement of transpyloric feeding tubes: A Comparision of $\mathrm{pH}$-assisted and Standard Insertion Techniques in Children. Pediatrics. 1996;98:242-8.

47. Sanko JS. Aspiration assessment and prevention in critically ill enterally fed patients: evidence-based recommendations for practice. Gastroenterology Nursing. 2004;27(6):279-85. http://dx.doi. org/10.1097/00001610-200411000-00007.

48. Turgay AS, Khorshid L. Effectiveness of the auscultatory and pH methods in predicting feeding tube placement. Journal of Clinical Nursing 2010;19:1553-9. http://dx.doi.org/10.1111/j.1365-2702.2010.03191.x

49. Elpern E, Killeen K, Talla E, Perez G, Gurka D. Capnometry and air insufflation for assessing initial placement of gastric tubes. American Journal of Critical Care. 2007;16:544-49.

50. Tho PC, Mordiffi S, Ang E, Chen H. Implementation of the evidence review on best practice for confirming the correct placement of nasogastric tube in patients in an acute care hospital. International Journal of Evidence Based Healthcare. 2011;9(1):51-60. http://dx.doi. org/10.1111/j.1744-1609.2010.00200.x.

51. Marshall AP, West SH. Enteral feeding in the critically ill: are nursing practices contributing to hypocaloric feeding? Intensive \& Critical Care Nursing 2006;22(2):95-105. http://dx.doi.org/10.1016/j.iccn.2005.09.004 .

52. Persenius MW, Hall-Lord M, Baath C, Larsson BW. Assessment and Documentation of Patients Nutritional Status: Perception of Registered Nurses and their Chief Nurses. Journal of Clinical Nursing. 2008;17:2125-36. http://dx.doi.org/10.1111/j.1365-2702.2007.02202.x.

53. Mirmiran P, Hosseinpour-Niazi S, Hamayeli Mehrabani H, Kavian F, Azizi F. Validity and reliability of a nutrition screening tool in hospitalized patients. Nutrition. 2011;27(6):647-52. http://dx.doi.org/10.1016/j.nut.2010.06.013.

54. Btaiche IF, Chan L, Pleva M, Kraft MD. Critical illness, gastrointestinal complications, and medication therapy during enteral feeding in critically ill adult patients. Nutrition in Clinical Practice. 2010;25(1):32-49. http://dx.doi. org/10.1177/0884533609357565.

55. Elamin EM, Camporesi E. Evidence-based Nutritional Support in the Intensive Care Unit. International Anesthesiology Clinics. 2009;47(1):121-38. http://dx.doi.org/10.1097/AIA.0b013e3181950055. 